\title{
Clinical and topographical range of callosal infarction: a clinical and radiological correlation study
}

\author{
Maurice Giroud, Raymond Dumas
}

\begin{abstract}
A prospective clinical and radiological correlation study was performed to determine the frequency, and the clinical and radiological features of callosal infarction. From 1 January 1993 to the end of December 1993282 cases of cerebral infarction seen in the Neurology service of the University Hospital of Dijon were studied prospectively. Eight cases with callosal ischaemic lesions were identified by CT and MRI. A callosal disconnection syndrome occurred in only five of eight patients, related to a single, large infarct or several infarctions in the anterior part of the corpus callosum. Clinical features were characterised by left ideomotor apraxia, construction apraxia, and left agraphia in all five cases. Alien hand was noted in only two cases. There were gait disorders in three cases with MRI features of multiple lacunes in a large part of the corpus callosum, and also the subcortical areas of both hemispheres. It is emphasised that callosal infarctions are not rare and that they contribute to the clinical features of strokes. As well as the classic incomplete callosal disconnection syndrome, these callosal ischaemic lesions may induce non-specific gait disorders.
\end{abstract}

$(\mathcal{F}$ Neurol Neurosurg Psychiatry 1995;59:238-242)

Keywords: infarction; corpus callosum; disconnection; gait disorders

Cerebrovascular disease has played a major part in the understanding of callosal dysconnection syndromes and enabled Liepmann and Maas to show the role of the callosal lesion in the genesis of unilateral apraxia. ${ }^{1}$ The anatomical and clinical correlations are not easy to demonstrate in many cases because infarction is not usually limited to the corpus callosum, and multiple infarctions often coexist. Early studies ${ }^{2}$ on callosal symptoms preceded MRI and CT but more recent studies have used these techniques. ${ }^{3}$ Lesions of the corpus callosum producing disturbances of higher brain function are often recognised as disconnection syndromes of which unilateral left hand apraxia, agraphia, and tactile anomia are the most common. ${ }^{124-6}$ Because of the absence of systematic studies on the range of clinical and imaging features of callosal infarction, we performed this population based MRI study to determine the prevalence of the involvement of the corpus callosum in ischaemic strokes and to establish the clinical features.

\section{Patients and methods}

From 1 January 1993 to the end of December 1993, we examined prospectively all the patients with ischaemic stroke admitted to the neurological service of the University Hospital of Dijon (France). ${ }^{7}$ Our aims were firstly, to detect a clinical callosal syndrome in any patient with the usual features of an ischaemic stroke, and secondly, to detect callosal infarction by CT and MRI. An ischaemic stroke was defined as an acute neurological deficit, lasting more than 24 hours, with spontaneous improvement.

Clinical symptoms related to a callosal syndrome were systematically collected by the five senior neurologists of the service according to established criteria. ${ }^{1-68}$ These were left hand ideomotor apraxia, left hand agraphia, left hand tactile anomia, left alien hand syndrome (as described by Brion and Jedynak ${ }^{9}$ with three characteristics: inability to recognise the arm as one's own when held by the other arm with the eyes closed; a feeling of loss of control of left arm movements; and personification of the left arm), left visual anomia, left auditory extinction, and alexia without agraphia.

Proximal and distal motor examination of the limbs, locomotor ability, sensory stretch reflex examination, visual examination, tests for language (fluency, repetition, writing, reading), buccolinguofacial apraxia, gnosias of famous faces, colours, right-left and finger test, visuospacial and visuoconstructive tasks (drawing a cube, orientation on a map of France), memory functions, frontal functions, and neglect (line bisection test, simultaneous application of sensory, visual, or auditory stimuli), were studied. An ischaemic stroke was defined by a hypodense abnormality on CT and by a hyposignal on T1 weighted image and a hypersignal on T2 weighted image with gadolinium uptake after day 7 on MRI. T1 weighted images were acquired on a 1.5 Tesla Siemens MRI machine, with a short TR (480 ms) and a short TE (15 ms), and T2 weighted images with a TR of $250 \mathrm{~ms}$ and a TE of $20 \mathrm{~ms}$. We determined the presence and the topographic localisation of callosal 
Figure 1 Areas supplied by the branches of the ACA: (1) orbitofrontal artery, (2) frontopolar artery, (3) anterior internal frontal artery, (4) middle internal frontal artery, (5) posterior internal frontal artery,

(6) paracentral artery

(7) precumeal artery,

(8) internal parietooccipital artery,

(9) callosomarginal artery, (10) pericallosal artery.

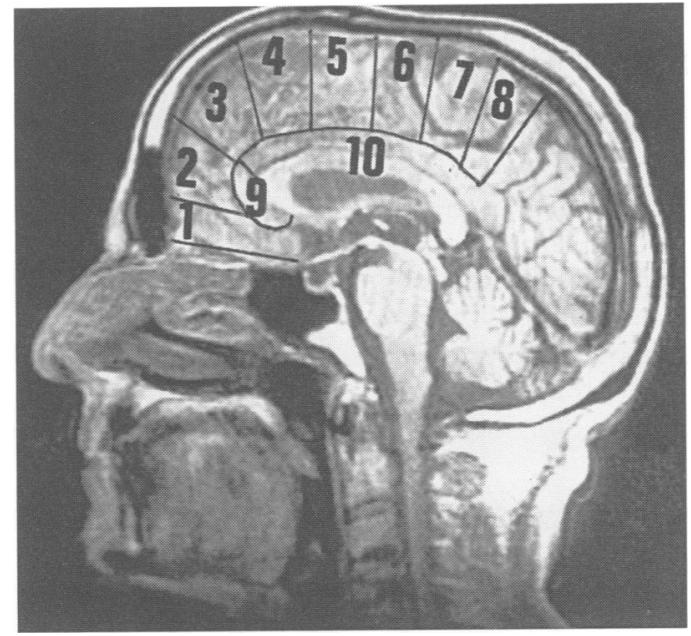

ischaemic stroke on CT with the templates defined by Matsui and Mirano ${ }^{10}$ and on MRI from the atlas of Duvernoy. ${ }^{11}$ Figure 1 shows the classification of the territory of the anterior cerebral artery (ACA) used. ${ }^{12}$ Doppler ultrasound examination of the cervical arteries, electrocardiography, and two dimensional transthoracic echocardiography were performed on all patients. Angiography was performed on 32. Serological and blood examinations excluded syphilis, hypercoagulability, hyperfibrinogenaemia, and homocystinaemia in all the patients. We prospectively collected data on age (years), sex, hypertension (systolic blood pressure greater than $160 \mathrm{~mm} \mathrm{Hg} / 90 \mathrm{~mm} \mathrm{Hg}$ ), diabetes mellitus (serum glucose greater than $1.40 \mathrm{~g} / \mathrm{l}$ ), dyslipidaemia (fasting cholesterol serum higher than $2.5 \mathrm{~g} / 1$ or fasting serum triglycerides greater than $1.5 \mathrm{~g} / \mathrm{l}$ ), cigarette smoking ( $\geqslant 20$ packs per year), previous stroke or transient ischaemic attack (focal cerebral dysfunction presumably ischaemic in origin lasting less than 24 hours without any sequelae), previous myocardial infarction with ECG sequelae, atrial fibrillation, presence of echocardiographic abnormalities such as left ventricular hypertrophy or akinesia, mitral valve prolapse, patent foramen ovale, or aneurysm of the interatrial septum, and significant atheroma of the internal carotid arteries (narrowing of $50 \%$ or more of the lumen as documented by Doppler ultrasonography). The presumed causes of stroke were defined according to the criteria used by Adams et al. ${ }^{13}$ Large vessel disease was considered as the cause of the infarcts when there was a stenosis of $50 \%$ or more in one carotid artery on Doppler ultrasonography or on angiography. Microangiopathy due to hypertension was diagnosed when infarction was in the territory of a deep perforating artery in the absence of another aetiology. Potential cardiac sources of embolism were considered if cardiac arrhythmia, valvulopathy, or cardiac failure with dilatation of ventricular cavities were present.

\section{Results}

Of 282 patients with ischaemic strokes collected during the 12 months, eight patients $(2 \cdot 7 \%$; three women, five men (mean age 68 , range 61 to 82 years)) had a radiologically identifiable callosal infarction. Four patients had a right sided associated cerebral infarct, one a left sided associated infarct, and three an infarction only in the corpus callosum. Table 1 summarises the clinical features and the radiological findings.

TWO MAIN PATTERNS OF CALLOSAL SYNDROME Classic callosal disconnection syndrome

Left hand apraxia was noted in six patients (3-8). It was easy to see in the patient (No 7) with right hemiplegia, but more difficult in the other five cases. All these six patients could not perform actions with their left hand on verbal commands after motor recovery. Four patients (5-8) also had impaired imitation and object use with the left hand on command. In these six patients, the body of the callosum was involved. The left hand apraxia was associated with a constructive apraxia. Alien hand syndrome occurred in only two patients, those with an extended callosal infarction (7 and 8).

Left hand agraphia was apraxic in four

Table 1 Clinical and MRI features of callosal infarction

\begin{tabular}{|c|c|c|c|c|c|c|c|c|c|c|}
\hline Patients & $\begin{array}{l}\text { Left } \\
\text { tactile } \\
\text { anomia }\end{array}$ & $\begin{array}{l}\text { Left } \\
\text { ideomotor } \\
\text { apraxia }\end{array}$ & $\begin{array}{l}\text { Left } \\
\text { agraphia }\end{array}$ & $\begin{array}{l}\text { Left } \\
\text { visual } \\
\text { anomia }\end{array}$ & $\begin{array}{l}\text { Left } \\
\text { hemideafness }\end{array}$ & $\begin{array}{l}\text { Constructive } \\
\text { apraxia }\end{array}$ & $\begin{array}{l}\text { Left } \\
\text { tactile } \\
\text { alexia }\end{array}$ & Alien hand & $\begin{array}{l}\text { Frontal } \\
\text { gait } \\
\text { disorders }\end{array}$ & MRI features \\
\hline 1 & 0 & 0 & 0 & 0 & 0 & 0 & 0 & 0 & + & \\
\hline 2 & 0 & 0 & 0 & 0 & 0 & 0 & 0 & 0 & + & \\
\hline 3 & 0 & + & 0 & 0 & 0 & + & 0 & 0 & + & \\
\hline 4 & 0 & + & 0 & 0 & 0 & + & 0 & 0 & 0 & \\
\hline 5 & 0 & + & + & 0 & + & + & 0 & 0 & 0 & \\
\hline 6 & 0 & + & + & 0 & 0 & + & 0 & 0 & 0 & \\
\hline 7 & + & + & + & 0 & 0 & + & + & + & 0 & \\
\hline 8 & 0 & + & + & 0 & 0 & + & 0 & + & 0 & \\
\hline
\end{tabular}

$\|$ I: associated internal frontal infarction. 
patients (5-8) because they had the ability of left hand writing with anagram letters. The right hand was neither agraphic nor apraxic in all of these cases. Left tactile anomia occurred in one case (No 7) with ischaemic lesions occurring within the four fifths of the corpus callosum and associated with internal frontoparietal ischaemia. Left visual anomia was not found. Left hemideafness as studied by the dichotic test, occurred in only one patient (No 5). Left tactile alexia was present in one patient (No 7).

\section{Gait disorders of frontal type}

Of eight patients with callosal infarction established by radiology, three had no specific clinical symptoms (Nos 1-3). The syndrome was characterised by gait disorders with locomotor difficulties of frontal type. The patients used a wide base with feet rooted to the ground. Gait consisted of shuffling with short steps (marche à petit pas) and freezing, with no arm swing, and slight extension of the trunk. In patient 1 , there were lacunes in the genu of the corpus callosum, in patient 2 , there were lacunes in the middle part of the corpus callosum. Patient 3 had a small infarction in the middle of the corpus callosum. All three patients had lacunes in the white matter of the centrum ovale.

\section{MOTOR DYSFUNCTION}

Patient 4 had crural monoplegia and hemiplegia was predominantly in the legs in patients 5-8.

\section{OTHER DEFICITS}

Hemihypoaesthesia ipsilateral to the hemiplegia was seen in patients 7 and 8 both on upper and lower limbs. Hemineglect was present and forced grasping occurred in the same two patients.

\section{STROKE TOPOGRAPHY}

Two types of ischaemic lesions were identified by CT and MRI: lacunes < $10 \mathrm{~mm}$ diameter in the corpus callosum associated with bilateral subcortical lacunes, in white matter in two patients ( 1 and 2 ; fig 2 ) and large infarctions in six patients ( 3 to 8 ), associated with leukoaraïosis in patient 3 (fig 3) and with a small infarction in the ipsilateral centrum ovale in patient 7 (fig 4). Patient 4 had two separated infarctions within the corpus callosum (fig 5). Patients 6 and 8 showed an anterior right corpus callosum infarction (fig 6) also involving the ipsilateral internal frontal area on MRI, corresponding to the ACA territory. Patient 5 had a large infarction in the middle part of the corpus callosum associated with a right internal frontal infarction on MRI, corresponding to the ACA territory. We found in total 13 cases of ACA territory infarctions out of 282 cerebral infarctions.

\section{RISK FACTORS (TABLE 2)}

Hypertension was the most frequent risk factor. It occurred alone in patients 1 and 2 and was associated with diabetes mellitus in patients 4 and 7 , with dyslipidaemia in

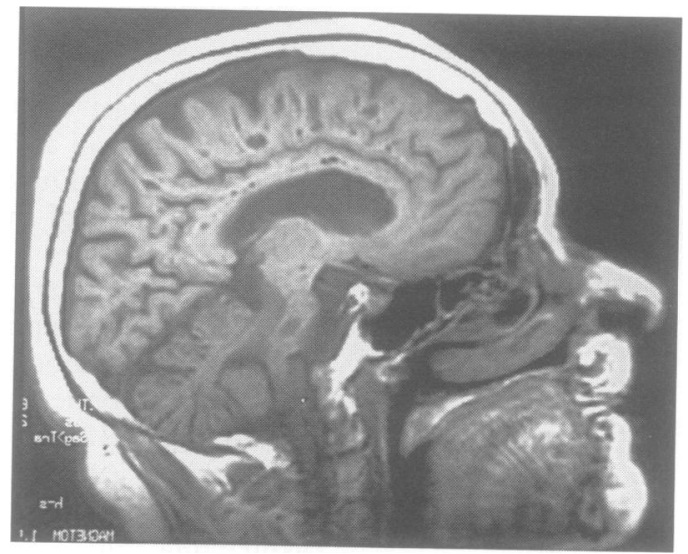

Figure 2 (patient 1) Several lacunes $<10 \mathrm{~mm}$ diameter all along the corpus callosum but also within the ovale centrum on sagittal T1 weighted MRI.

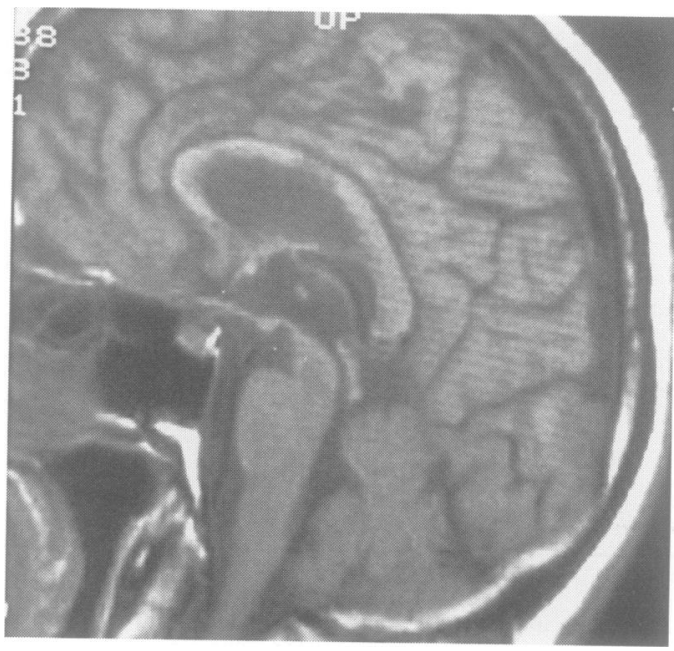

Figure 3 (patient 3) Large infarct in the middle of the corpus callosum, on sagittal T1 weighted MRI.

Table 2 Deficits, risk factors and causes of stroke in the patients with callosal infarction

\begin{tabular}{|c|c|c|c|c|c|c|c|}
\hline Patients & Sex & Age (years) & Hemiplegia & Hemihypoaesthesia & Other deficits & Risk factors & $\begin{array}{l}\text { Presumed } \\
\text { cause } \\
\text { of stroke }\end{array}$ \\
\hline $\begin{array}{l}1 \\
2 \\
3 \\
4 \\
4 \\
5 \\
6 \\
7 \\
8\end{array}$ & $\begin{array}{l}\mathrm{F} \\
\mathrm{M} \\
\mathrm{M} \\
\mathrm{F} \\
\mathrm{M} \\
\mathrm{M} \\
\mathrm{F} \\
\mathrm{M}\end{array}$ & $\begin{array}{l}63 \\
68 \\
61 \\
69 \\
82 \\
72 \\
62 \\
69\end{array}$ & $\begin{array}{l}0 \\
0 \\
0 \\
\text { Left } L \\
\text { Left } U+L \\
\text { Left } U+L \\
\text { Right } U+L \\
\text { Left } U+L\end{array}$ & $\begin{array}{l}0 \\
0 \\
0 \\
0 \\
0 \\
0 \\
\text { Right } U+L \\
\text { Right } U+L\end{array}$ & $\begin{array}{l}0 \\
0 \\
0 \\
0 \\
0 \\
0 \\
\text { FG + HN } \\
\text { FG + HN }\end{array}$ & $\begin{array}{l}\mathrm{HT} \\
\mathrm{HT} \\
0 \\
\mathrm{HT}+\mathrm{DM} \\
\mathrm{HT}+\mathrm{DL}+\mathrm{CA} \\
\mathrm{HT}+\mathrm{DL}+\mathrm{CA} \\
\mathrm{HT}+\mathrm{DM}+\mathrm{DL}+\mathrm{CA} \\
\mathrm{A}+\mathrm{HT}\end{array}$ & $\begin{array}{l}\text { SVD } \\
\text { SVD } \\
\text { SVD } \\
\text { SVD } \\
\text { LVD } \\
\text { LVD } \\
\text { LVD } \\
\text { CE }\end{array}$ \\
\hline
\end{tabular}

$\mathrm{CA}=$ carotid atheroma; $\mathrm{SVD}=$ small vessel disease; $\mathrm{LVD}=\mathrm{HN}=$ hemineglect; $\mathrm{A}=$ arythmia; $\mathrm{DL}=$ dyslipidaemia; $\mathrm{DM}=$ diabetes melitus; $\mathrm{HT}=$ hypertension; 

Figure 4 (patient 7)
Infarction involving the left posterior part of the corpus callosum and the ovale centrum, on horizontal T2 weighted MRI.

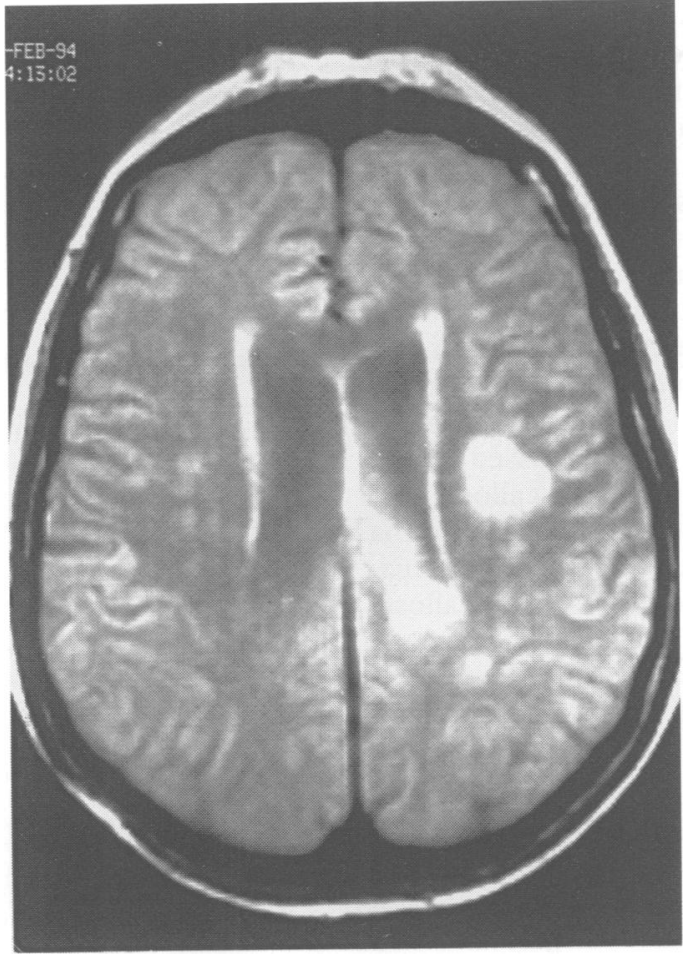

Figure 5 (patient 4) Two small infarctions in the middle of the corpus callosum on sagittal $T 1$ weighted MRI.
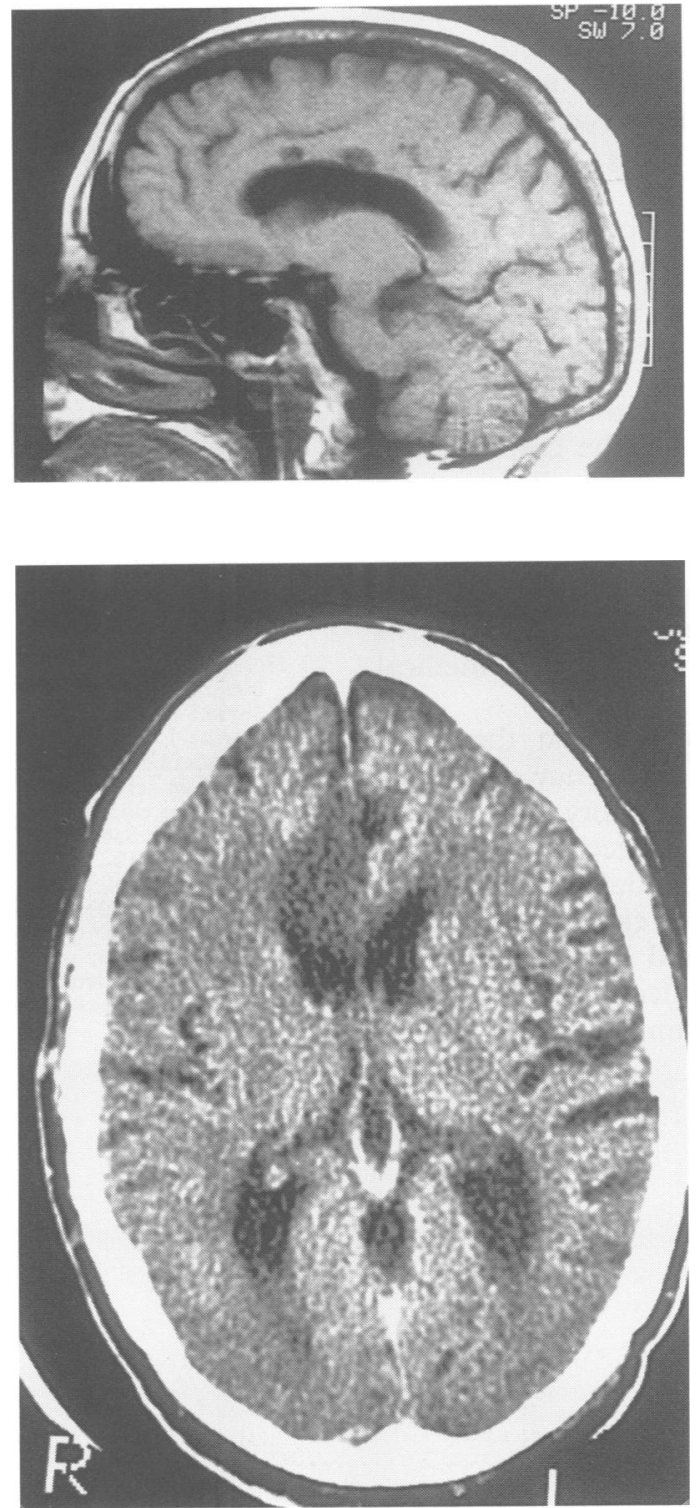

patients 5,6 , and 7 , with stenosis of the internal carotid artery in patients 5 and 6 , and with atrial fibrillation in patient 8 . Patient 3 had no apparent risk factors.

PRESUMED CAUSES OF STROKE (TABLE 2)

Small vessel occlusion was presumed to be the cause of the callosal infarction in four patients (1-4), large vessel occlusion in three patients (5-7), and cardioembolism in one patient (8).

\section{Discussion}

Previous studies based on CT and on selected postmortem studies have underestimated the frequency of infarction of the corpus callosum. By using MRI in a well defined cohort study, it is possible to know exactly the extent of callosal involvement in comparison with other anatomical structures implicated in ischaemic stroke. We found 13 patients with ACA territory infarctions out of 282 ischaemic strokes $(4 \cdot 6 \%)$. These data are similar to the $4 \%$ found by Bogousslavsky et al ${ }^{14}$ in another hospital based study. Among these 13 patients we recorded eight $(61 \%)$ cases of callosal infarction by CT and MRI, a percentage similar to that found by Bogousslavsky and Regli, ${ }^{3}$ but greater than the $36 \%$ reported by Hung and Ryu $^{8}$ before MRI was available.

The earliest descriptions of the supply areas of the ACA were by Duret in $1874,{ }^{15}$ by Foix and Hillemand in $1925,{ }^{12}$ and Critchley in $1930 .^{2}$ The ACA irrigates the medial surface of the frontal and parietal lobes, the anterior limb of the internal capsule, the head of the caudate, and the corpus callosum (fig 1). Infarction of the entire vascular territory of the ACA is rare (4\%). ${ }^{8}$ In most instances, the infarction is subtotal, involving individual branches, singly or in combination.

Despite advances in diagnostic technology, involvement of the corpus callosum in ACA syndromes has not been well recognised on epidemiological, clinical, or radiological grounds. ${ }^{16-18}$ There are many reasons for this: spontaneous onset of callosal infarction is rare, ${ }^{19}$ manifestations depend largely on the site and size of the infarct, which is related to the site of occlusion, and motor dysfunction may hide the neuropsychological effects of a lesion in the corpus callosum. In 1907, Liepmann and Maas ${ }^{1}$ described a 70 year old carpenter who had transcortical motor aphasia, apraxia, and agraphia of the left arm, and right hemiplegia. The left apraxic hand did not improve with imitation or actual object usage, and the left hand agraphia did not improve with the use of anagram letters. A postmortem examination showed a left ACA infarction with damage extending from the first frontal convolution through the white matter to the paracentral lobule with involvement of the anterior two thirds of the corpus callosum. A callosal lesion would disconnect the left hemisphere from the right premotor cortex and cause apraxia isolated to the left hand. ${ }^{21} 22 \mathrm{We}$ found ideational apraxia and construction apraxia exclusively limited to the left extremities.

Only two patients (7 and 8) showed alien 
hand signs. ${ }^{923}$ These had been thought to be secondary to callosal dysfunction but recently were attributed to damage of the medial frontal cortex, including the supplementary motor area and cingulate gyrus controlateral to the alien hand. ${ }^{23}$ This correlation was clear in patients 7 and 8. Grasp reflex and motor or verbal perseveration were found in these two patients. Therefore, infarction localised to the anterior one third of the corpus callosum was associated with an ideomotor apraxia and a construction apraxia as shown by patients 3-8. When infarction encompassed more than the anterior two thirds of the callosal corpus, we found an associated tactile anomia (patient 7). There was no visual anomia, because no case showed a posterior callosal lesion.

As well as the well known classic callosal disconnection syndrome, we have identified a pure gait disorder syndrome related to lacunes in the anterior part of the corpus callosum. The gait disorder with locomotor difficulty described in this paper seems to be a frontal type, ${ }^{24}$ with small step height or "marche à petits pas", with a wide base, a reduced number of steps per minute, with the feet rooted to the ground, shuffling with short steps and freezing, with imbalance, loss of arm swing, and slight extension of the trunk. The patients have considerable difficulties initiating the leg movements required to walk (yet can perform the movements of pedalling a bicycle well when lying on the bed), and turn. This impairment of gait may be related to an involvement of efferents from the leg area of the motor cortex. ${ }^{24}{ }^{25} \mathrm{We}$ think that the lacunes in the anterior part of the corpus callosum may compromise the afferent pathways from the minor forceps to the frontal cortex, but lacunes outside the corpus callosum could explain this gait disorder in three patients. The last question focuses on the fact that lacunes may be present within the corpus callosum due to involvement of perforating branches of the ACA and this localisation is underestimated in the medical literature. ${ }^{26} 27$

In summary, MRI shows that there has been an underestimated frequency of callosal infarction in ACA territory infarction. Secondly, the callosal infarction may contribute to the neurological deficit. Thirdly, as well as the classic anterior callosal disconnection syndrome, we found gait disorders in patients with lacunes affecting the anterior part of the corpus callosum.
1 Liepmann $\mathrm{H}$, Maas $\mathrm{O}$. Fall von linksseitiger agraphie und apraxie bei rechtsseitiger Lähmung. $尹$ Psychol Neurol 1907;10:214-30.

2 Critchley $M$. The anterior cerebral artery and its syndromes. Brain 1930;53:120-65.

3 Bogousslavsky J, Regli F. Infarctus du territoire de l'artère cérébrale antérieure gauche. I. Corrélations clinicotomodensitométriques. Rev Neurol (Paris) 1987;143: 21-31.

4 Geschwing N, Kaplan E. A human cerebral deconnection syndrome. A preliminary report. Neurology 1962;12. syndrom

5 Watson RT, Heilman KM. Callosal apraxia. Brain 1983; 106:391-403.

6 Bogen JE. Split-brain syndromes. In: Frederiks JAM, ed Handbook of clinical neurology. Vol 1 (45): Clinical neuropsychology. Amsterdam: Elsevier, 1985:99-106.

7 Giroud M, Milan C, Beuriat P, Gras P, Essayagh E, Arveux $P$, Dumas $R$. Incidence and survival rates during a two year period of intracerebral and subarachnoid haemorrhages, cortical infarcts, lacunes, and transient iscomicts 1895-1989. Int $\mathcal{f}$ Epidemiol 1991;20:892-9.

8 Hung TP, Ryu SJ. Anterior cerebral artery syndromes. In: JF Toole, ed. Handbook of clinical neurology. Vascular disJF Toole, ed. Handbook of clinical neurology. Vas

9 Brion S, Jedynak CP. Les troubles du transfert inter-hémisphérique. Rev Neurol (Paris) 1972;126:
19. Jedynak CP. Les troubles du transfert 257-66.

10 Matsui-T, Hirano A. An atlas of human brain for CT. Tokyo: Igaku-Schoin, 1978.

11 Duvernoy HM. Le cerveau humain. Surface, coupes sériées tridimensionnelles et IRM. Paris: Springer-Verlag, 1992.

12 Foix C, Hillemand P. Les syndromes de l'artère cérébrale antérieure. Encéphale 1925;20:209-32.

13 Adams HP, Bendixen BH, Kappelle LJ, Biller J, Love BB, Gordon DL. Marsh EEIII, and the TOAST investigations. Classification of subtypes of acute ischemic stroke: definitions for use in a multicenter clinical trial. Stroke definitions for 1 .

14 Bogousslavsky J, Van Melle G, Regli F. Stroke registry: analysis of 1000 consecutive patients with first stroke. Stroke 1988;19:1083-92.

15 Duret $H$. Recherches anatomiques sur la circulation de l'encéphale. Arch Physiol Norm Pathol (2 ème série). 1874;1:316-54.

16 Bories J, Derhy S, Chiras J. CT in hemispheric ischaemic attacks. In: J Bories, ed. Cerebral ischaemia. $A$ neuroradiological study. Berlin: Springer Verlag, 1985: 18-33.

17 Ryu SJ. The Chang Gung stroke registry. Chang Gung Med f 1986;9:204-16.

18 Radü EW, Moseley IF. Carotid artery occlusion and computed tomography: a clinicoradiological study. Neuroradiology. 1978;17:7-12.

19 Habib M, Ceccaldi C, Poncet M. Syndrome de déconnexion calleuse par infarctus jonctionnel déconnexion calleuse par infarctus jonctionnel 19-24.

20 Heilman KM. Apraxia. In: Heilman KM, Valenstein E, eds. Clinical neuropsychology. New York: Oxford University Press, 1979:159-85.

21 Geschwind N. The apraxias: neural mechanisms of disorders of learned movement. American Scientist 1975;63: 188-95.

22 Yamadori A, Osumi Y, Ikeda H, Kanazawa Y. Left unilateral agraphia and tactile anomia. Disturbances seen after occlusion of the anterior cerebral artery. Arch Neurol 1980;37:88-91.

23 Goldberg G, Mayer NH, Toglia JV. Medial frontal cortex infarction and the alien hand sign. Arch Neurol 1981; 38:683-6.

24 Sudarsky L, Simon S. Gait disorder in late-life hydrocephalus. Arch Neurol 1987;44:263-7.

25 Fisher CM. Hydrocephalus as a cause of disturbance of gait in the elderly. Neurology 1982;32:1358-63.

26 Chamorra A, Sacco RL, Mohr JP, Foulkes MA, Kase CS Tatemichi TK, et al. Clinical-computed tomographic correlations of lacunar infarction in the Stroke Dat Bank. Stroke 1991;22:175-81.

27 Yamanchi H, Fukuyama H, Ogawa M, Ouchi Y, Kimura J. Callosal atrophy in patients with lacunar infarction and extensive leukoaraîosis. An indicator of cognitive impairment. Stroke 1994;25:1788-92. 